iridectomy in chronic glaucoma provided the central vision is fairly good and there is not too much contraction of the field, but one is sometimes, perhaps, inclined to rely for too long a time on myotics in the very early stage of the disease, lest after the performance of iridectomy with its possible resulting astigmatism the sight might be left rather worse than it was before the operation and so cause the patient to be disappointed with the result and dissatisfied with the surgeon.

IIr. Cross's suggestion to perform sclerotomy rather than iridectomy in the very early stage of the disease might, I think, in some cases be advisable, as there would probably be less disturbance of vision from that operation than where a large piece of iris had been removed, and iridectomy conld always eventually be performed if necessary. I should not have troubled you with this letter were it not that the operative treatment of chronic glancoma is not now, as far as I am aware, open to question, so that the remarks erroneously attributed to me are entirely contrary to what is now a well-established fact.

I am, Sirs, yours faithfully,

Gloucester, August 12th, 1900.

E. DYKeS BOWER.

\section{THE COVENTRY DISPENSARY,}

\section{To the Editors of THE LANCET.}

SIBS,-In THE LANCET of August 4th I notice a report of a discussion at the Deontological Congress in Paris where a Mr. Adolphe Smith is reported to have said that a combination of the local profession against certain " ostracised" practitioners in Wolverhampton and Coventry failed owing to the support these received from Birmingham consultants. I should like to know what are the facts which support this statement or whether there is any inaccuracy in the report. I have never heard of any "ostracised" practitioners in Wolverhampton nor do I think this term is rightly applied to the staff of the Coventry Dispensary. I have never been asked to support the profession in either town against any individuals nor do I know that a request of this kind has been brought before any of our medical societies by either of these towns. Such support was asked by another neighbouring town and at a meeting of the Birmingham and Midland Counties Branch of the British Medical Association it was agreed to, and I believe the boycott had the desired effect.

If I am not mistaken Mr. Adolphe Smith is the same gentleman who three years ago made certain statemerts about the profession in Birmingham which he failed to sub. stantiate when challenged. So far as my knowledge goes his present allegations are equally baseless.

I am, Sirs, yours faithfully,

Llantrindod Wells, August 10th, $1900 . \quad$ ROBERT SAUNDBY.

** We have every reason to believe that $\mathrm{Mr}$. Adolphe Smith knows what he is talking about. Some three years ago Dr. Saundby wrote a letter in our columns containing offensive allusions to our Commissioner's work. If this letter is what he now refers to as a challenge it is well that he should understand that it was not answered either by our Oommissioner or by ourselves because it was rude.-ED. L.

\section{PARIS.}

(FROM OUR OWN CORRESPONDENT.)

Three New Hospitals.

THE Assistance Publique will be able before the end of the year to open three new hospitals for children built to replace the Trousseau Hospital which will be pulled down as soon as certain legal formalities have been complied with (après désaffectation). The building are almost complete and the children will be admitted as soon as the plaster is dry. The new hospitals are built of brick in accordance with all the most modern ideas and contain altogether 700 beds. Their names are as follows: the Herold in the Place de Danube, the Trousseau in the Rue Michel Bizot, and the Bretonneau in the Rue Carpeanx. Including the Hospital for Sick Children in the Rue de Sères, formerly called the Hôpital de l'Enfant$J$ sus, Paris will have four hospitals for children at convenient distances apart, so that mothers will not have to go very far for consultation. The last-mentioned hospital has been considerably enlarged and last year some isolation wards were built which are looked upon as models of construction and fitting. Paris will henceforth be able to offer opportunities for the study of children's diseases such as few other towns in the world can afford.

The Monument to Pelletier and Caventou.

A monument in memory of Pelletier and Caventou, the two discoverers of quinine, has just been erected. It stands in the Boulevard Saint Michel at the corner of the Rue de l'Abbé de l'Epée, close to the School of Pharmacy, and was unveiled on August 7th in great state at 10 o'clock in the morning. M. Marty, a member of the Academy of Medicine, handed over the monument to the town of Paris and $M$ Edmond Lepelletier returned thanks in the name of the Municipality. The two chemists are represented as standing upon one pedestal. The expenses were defrayed by a subscription among the members of the Pharmaceutical Section of the Academy of Medicine and by the Syndicate of Pharmacists.

The Relations between the Thyroid Gland, the Hair, and the Genital Oryans.

M. Gautier, who has been pursuing his researches upon organic arsenic, communicated his latest results to the Academy of Medicine at the meeting held on August 7th. Normal blood contains very little arsenic or iodine, but it is otherwise with menstrual blood, except the menstrual blood of anæmic patients. At every period the thyroid gland discharges nearly the whole of its arsenic. Iodine is four and half times more abundant in menstrual blood than in normal blood. Both elements have their origin in the thyroid 'gland which establishes a relation between this gland and the menses and is at the same time a confirmation of the relation anciently said to exist between the thyroid body and the genital organs. In the lower animals the arsenical nucleins of the thyroid in. crease the growth of the hair and this increase is specially marked between the rutting periods. In men these nucleins are devoted to the growth of the hair and beard, not having to be eliminated by the menses as in women. Women treated with the cacodylates show an increased growth of the hair and the menstrual flow becomes more abundant. In tuberculous patients the arsenic and iodine may disappear from the thyroid, and hence affections of the hair and skin in such patients can be improved by administering these elements. These facts explain the favourable influence of arsenic upon cutaneous affection and apon the growth of the hair. Replying to the objection of MI. Fournier, who said that he had never seen a case of cure of prurigo gestationis, or for the matter of that of any skin disease by arsenic, M. Gautier said that he never used mineral arsenic but only arsenic in the form of the cacodylates.

August 14th.

\section{BERLIN.}

(FROM OUR OWN CORRESPONDENT.)

Statistics of Diabetes.

DR. GEORG HEIMANN of Berlin has published in the Deutsche Medicinische Wochenschrift some interesting statistics of the frequency of diabetes in Prussia. The number of deaths from this disease in Prussia as given by the Royal Statistical Office was 12,929 during the period from 1877 to 1897 and of these $4889-37.8$ per cent.- were deaths of females. On an average 378 persons died from diabetes annually from 1877 to 1886 , of whom 237 were males and 141 were females. From 1887 to 1896 the average annual number of deaths was 796, 494 being males and 302 being females. In 1897 the deaths were 1186, 735 being males and 451 being females. In 1877, 1887, and 1897 the death-rates of males per 100,000 of the male population were $1 \cdot 0,2 \cdot 4$, and $4 \cdot 7$ respectively, the corresponding death-rates for females per 100.000 of the female population being $0.7,1.6$, and 2.8 respectively. The increase of mortality from diabetes is due probably to a better knowledge of the disease, the diagnosis being made now in a greater number of cases. 'l'here are certainly many more cases than are recorded in the official tables owing to the deficiency of death certificates in country places, and it is very significant that of 1186 deaths 